\title{
CARACTERÍSTICAS E DIFICULDADES DO NATURALISMO BIOLÓGICO DE JOHN SEARLE ${ }^{1}$
}

Tárik de Athayde Prata (UFS) ${ }^{2}$

tarikbilden@yahoo.de

Resumo: $\mathrm{O}$ artigo visa realizar uma exposição geral da solução de John Searle para o problema mente-corpo - o naturalismo biológico - examinando suas teses fundamentais e uma série de implicações destas. $O$ exame dessas teses - que delineiam as características da teoria de Searle - e de suas consequências mostra que a teoria cai em três grandes dificuldades por defender asserções que, à primeira vista, parecem incompatíveis.

Palavras-chave: Problema mente-corpo, Searle, redução, causação mental.

\section{RECONSTRUINDO A TEORIA DE SEARLE}

Há cerca de três décadas John Searle defende uma concepção dos fenômenos mentais que, segundo ele, é consistente com as evidências do nosso cotidiano e com os conhecimentos fornecidos pelas ciências da natureza. Já em Intrinsic Intentionality, sua réplica às críticas publicadas conjuntamente com seu famoso artigo Minds, Brains, and Programms (1980a, sua primeira e, até hoje, mais influente contribuição à filosofia da mente), o autor defende as linhas básicas da mesma concepção que encontramos em seus textos mais

\footnotetext{
${ }^{1}$ Artigo recebido em 30.01.2010 e aprovado em 19.08.2010.

${ }^{2}$ Tárik de Athayde Prata é Professor adjunto do Departamento de Filosofia da Universidade Federal de Sergipe, São Cristóvão, Brasil.
} 
recentes. Ele (1980b, p. 453) apresenta os fundamentos de sua teoria da seguinte maneira:

Mas quais são as minhas premissas? Elas são coisas como: que as pessoas têm estados mentais como crenças, desejos e experiências visuais, que elas também têm cérebros, e que seus estados mentais são os produtos causais da operação de seus cérebros. ${ }^{3}$

A última afirmação nessa passagem é muito importante para a teoria em questão. Embora a ideia de uma suposta causação dos fenômenos mentais por processos cerebrais seja alvo de intensas críticas no debate sobre a filosofia de Sear$\mathrm{le}^{4}$, ela é, no meu entender, importante para ele porque a suposta relação causal nos permitiria (segundo o autor) explicar a existência dos fenômenos mentais e suas características - consciência, intencionalidade, subjetividade e eficácia causal, entre outras - nos mesmos termos em que nós explicamos outras propriedades sistêmicas da natureza (cf. SEARLE, 1984, p. 22). A ideia de uma explanação causal dos fenômenos mentais através do funcionamento do cérebro é explicitamente apresentada por Searle (1992, p. 100) como uma das condições para a solução do problema mente-corpo:

Se tivéssemos uma ciência do cérebro adequada, uma descrição do cérebro que fornecesse explanações causais da consciência em todas as suas formas e variações, e se superássemos nosso erros conceituais, não restaria nenhum problema mente-corpo. (grifo meu $)^{5}$

\footnotetext{
${ }^{3}$ As citações em inglês foram traduzidas pelo autor deste artigo.

${ }^{4}$ Cf. Thompson (1986, p. 95); Churchland (1994, p. 14); Kim (1995, p. 194).

${ }^{5}$ A ciência do cérebro, por um lado, e a superação dos erros conceituais, por outro, correspondem, respectivamente, à parte empírica e à parte filosófica do problema mente-corpo, discutidas na seção denominada "O problema da explanabilidade". Nessa seção também será discutido em que medida o modo como Searle concebe a explanação causal é adequado.
} 
Desde o início de seu trabalho em filosofia da mente, Searle se afastava das influentes concepções segundo as quais dizer que alguém possui estados mentais é simplesmente atribuir a esse alguém disposições de comportamento, ou adotar certo tipo de atitude em relação a ele. Sua postura realista em relação à mente, em suas palavras, "não dá ao mental uma 'divina aura cartesiana', ela apenas implica que processos mentais são tão reais quanto outros processos biológicos” (SEARLE, 1980b, p. 453). A tentativa de Searle é a de evitar o vocabulário e as categorias tradicionais a respeito do problema mente-corpo, que, segundo ele, opõem indevidamente o mental ao físico, e simplesmente enunciar os fatos tais como nós os conhecemos. Naquele texto de 1980 ele esboça as linhas gerais de sua concepção da mente usando termos que até hoje se encontram em seus escritos:

Minha própria - e bastante experimental [tentative] - imagem é esta. Estados mentais são tão reais quanto outros fenômenos biológicos. Eles são causados e realizados no cérebro. Isso não é mais misterioso do que o fato de propriedades como elasticidade e a resistência a perfurações de um pneu de carro cheio são causadas e realizadas na microestrutura. (SEARLE, 1980b, p. 455)

Anos depois, no capítulo final de seu livro Intentionality: An Essay in the Philosophy of Mind, o autor oferece a designação de "naturalismo biológico" para sua teoria ${ }^{6}$, que, desde então, é empregada em seus escritos sobre o problema mentecorpo. $\mathrm{O}$ naturalismo biológico pode ser entendido como a tese geral de que os fenômenos mentais são fenômenos bio-

\footnotetext{
6 "Na minha concepção [account], estados mentais são tão reais quanto quaisquer outros fenômenos biológicos, tão reais quanto a lactação, a fotossíntese, a mitose ou a digestão. Como esses outros fenômenos, estados mentais são causados por fenômenos biológicos e causam por sua vez outros fenômenos biológicos. Se alguém quiser um rótulo, pode chamar tal concepção de 'naturalismo biológico”' (SEARLE, 1983, p. 264).
} 
lógicos ${ }^{7}$ ou, como as duas teses mais específicas, absolutamente centrais para essa concepção, segundo as quais os fenômenos mentais são causados por microprocessos cerebrais e realizados na estrutura do cérebro ${ }^{8}$. A primeira tese, a da causação da consciência por processos cerebrais, tem uma série de consequências importantes, pois, de acordo com Searle, ela acarreta a redutibilidade causal da consciência aos processos cerebrais que a causam ${ }^{9}$. Essa redutibilidade causal é apresentada por ele (2002b, p. 60) em um escrito mais recente:

Consciência é causalmente redutível a processos cerebrais, porque todas as características da consciência são causalmente explicáveis por processos neurobiológicos ocorrendo no cérebro, e a consciência não tem capacidades causais por si mesma em adição às capacidades causais da neurobiologia subjacente. (grifos meus)

Trata-se, por um lado, da possibilidade de se obter a acima mencionada explanação causal das características da consciência $^{10} \mathrm{em}$ termos de processos cerebrais e, por outro, do fato de que as capacidades causais da consciência seriam idênticas às dos processos cerebrais subjacentes (cf. PRATA, 2008b, p. 9-13). As duas condições para a redução causal da consciência, que seriam uma consequência do fato de esta ser causada por processos cerebrais, levantam uma série de dificuldades quando é considerada uma quarta tese absoluta-

\footnotetext{
7 "Eventos e processos mentais são tão parte de nossa história natural biológica quanto a digestão, a mitose, a meiose ou a secreção de enzimas” (SEARLE, 1992, p. 1).

8 "Nós podemos resumir o naturalismo biológico de maneira muito simples em duas proposições: (1) cérebros causam a mente; (2) mentes são características de nível superior do cérebro" (SEARLE, 1994, p. 545).

9 "Eu sustento uma visão das relações mente-cérebro que é uma forma de redução causal, tal como eu defini a noção: características mentais são causadas por processos neurobiológicos” (SEARLE, 1992, p. 115).

${ }^{10}$ Nos primeiros escritos do autor sobre filosofia da mente, Searle formulava suas teses a respeito dos fenômenos (estados, eventos, processos) mentais. Em textos posteriores, elas dizem respeito à consciência. Isso se deve ao fato de, em escritos mais recentes, ele assumir a posição de que a consciência é o mais importante dos fenômenos mentais (cf. p. ex. SEARLE, 1992, p. 18; 84).
} 
mente central para o naturalismo biológico de Searle, a de que a consciência, diferente de tudo mais no universo, possui um modo de existência subjetivo, pois só existe quando é vivenciada por um sujeito (cf. SEARLE, 2002a, p. 40-41).

Os problemas começam porque esta tese, exatamente ao contrário das três teses anteriores, parece ter como consequência que a consciência é algo diferente dos processos cerebrais. A tese do modo subjetivo de existência da consciência pode ser reformulada como a afirmação de que a consciência é ontologicamente irredutivel à atividade cerebral, e a irredutibilidade ontológica tem implicações que parecem incompatíveis com a redutibilidade causal anteriormente exposta. Searle (1992, p. 117) formula a irredutibilidade ontológica como se segue:

Agora, suponha que tentássemos reduzir a sensação de dor subjetiva, consciente, de primeira pessoa, aos padrões de descargas neuronais objetivas, de terceira pessoa. Suponha que tentássemos dizer que a dor é na verdade "nada exceto" os padrões de descargas de neurônios. Bem, se tentássemos uma tal redução ontológica, as características essenciais da dor seriam deixadas de lado. Nenhuma descrição dos fatos de terceira pessoa, objetivos, fisiológicos, expressaria [convey] o caráter subjetivo, de primeira pessoa, da dor, simplesmente porque as características de primeira pessoa são diferentes das características de terceira pessoa. (grifos meus)

Assim, na concepção de Searle, a irredutibilidade ontológica acarreta a impossibilidade de se exprimir as características da consciência através da descrição da atividade cerebral, em virtude do fato de que as características subjetivas e objetivas são diferentes.

Finalmente, para reconstituir as teses fundamentais do naturalismo biológico, não se pode deixar de lado uma concepção defendida por Searle (1980b, p. 455; 1983, p. 
270; 2002b, p. 61-62) em toda a sua obra sobre filosofia da mente: a eficácia causal dos estados de consciência, o que significa que tais estados estão envolvidos na produção das ações humanas. Em uma passagem na qual ele resume sua teoria da mente, Searle (2004, p. 114) escreve: "Porque estados mentais são características reais do mundo real, eles funcionam causalmente. Minha sede consciente me leva a [causes me] beber água, por exemplo”.

Para sintetizar a exposição realizada acima e lançar as bases da discussão a ser realizada no prosseguimento do presente trabalho, seguirei um procedimento utilizado pelo próprio Searle (1994, p. 545; 2003, p. 113-114), que é o de apresentar o naturalismo biológico como um conjunto de teses, o que já foi feito também por diversos comentadores de sua obra (cf. CORCORAN, 2001; NIDA-RÜMELIN, 2002):

(1) A consciência é causada por processos cerebrais

(1') As características da consciência são causalmente explicáveis através dos processos cerebrais

(1") As capacidades causais da consciência são idênticas às dos processos cerebrais

(2) A consciência é realizada no sistema cerebral

(3) A consciência é um fenômeno biológico

(4) A consciência possui um modo de existência (ontologia) subjetivo

(4b) A consciência é ontologicamente irredutivel a fenômenos objetivos

(4b') As características da consciência não podem ser expressas em termos objetivos 
(4b”) As características subjetivas e objetivas são diferentes

(5) A consciência é causalmente eficaz ${ }^{11}$

A análise das cinco teses fundamentais do naturalismo biológico e de suas consequências evidencia diversos problemas no tocante à sua compatibilidade, problemas que podem ser divididos em três grupos: a) o problema da explanabilidade; b) o problema das capacidades causais; c) o problema da identidade.

\section{O PROBLEMA DA EXPLANABILIDADE}

O problema relativo à explanabilidade das características da consciência surge da aparente incompatibilidade de duas teses constituintes do naturalismo biológico, a saber, as teses (1') e (4b'). Por um lado, Searle afirma que "As características da consciência são causalmente explicáveis através dos processos cerebrais" e, ao mesmo tempo, defende que "As características da consciência não podem ser expressas em termos objetivos". A tensão se coloca claramente entre a possibilidade de explicar e a impossibilidade de exprimir. Se as características da consciência não podem sequer ser expressas em vocabulário objetivo (como é objetivo o vocabulário usado nas neurociências) como poderiam essas características ser explicadas através de processos cerebrais? Mesmo considerando a admissão por Searle de que explicações causais da consciência através da atividade cerebral ainda não

\footnotetext{
${ }^{11}$ As teses cujo número é seguido por' ou ", são consequências da tese imediatamente anterior. A tese cujo número é seguido por $b$ é uma reformulação da tese imediatamente anterior.
} 
estão ao nosso alcance ${ }^{12}$, a incompatibilidade entre as teses (1') e (4b') é um sério obstáculo para a teoria dele, pois esta parece tornar inviável que um dia uma explicação desse tipo possa ser alcançada.

Também é importante considerar que, ao argumentar a favor do princípio da conexão entre consciência e intencionalidade (cf. Capítulo 7 de The Rediscovery of the Mind), Searle afirma que a forma aspectual dos estados intencionais ${ }^{13}$, isto é, os determinados aspectos pelos quais um estado intencional representa suas condições de satisfação ${ }^{14}$, não pode ser exaustiva ou completamente caracterizada por predicados objetivos. De acordo com o autor (1992, p. 157158, grifos no original):

A característica aspectual não pode ser exaustiva ou completamente caracterizada apenas em termos de predicados de terceira pessoa, comportamentais ou mesmo neurofisiológicos. Nenhum destes é suficiente para dar uma explicação exaustiva da forma aspectual.

Mas, se é assim, se predicados neurofisiológicos são insuficientes para caracterizar a forma aspectual, parece inviável que uma teoria neurofisiológica pudesse explicar porque um estado intencional (com uma determinada forma aspectual) teria de ser gerado por um determinado processo cerebral.

Se se consideram essas duas afirmações de Searle (uma relativa à consciência e a outra relativa à intencionalidade, que, segundo ele, é essencialmente ligada à primeira), pode-se ca-

\footnotetext{
12 "Neurobiologicamente falando nós estamos apenas começando" (SEARLE, 1994, p. 545).

${ }^{13}$ Explicando a forma aspectual o autor dá o seguinte exemplo: "a crença de que a torre Eiffel está em Paris representa suas condições de satisfação sob certos aspectos e não outros. Ela é, por exemplo, distinta da crença de que a mais alta estrutura de ferro construída na França antes de 1900 está localizada na capital francesa, mesmo assumindo que a torre Eiffel é idêntica à mais alta estrutura de ferro construída na França antes de 1900, e que Paris é idêntica à capital francesa" (SEARLE, 1992, p. 155).

${ }^{14}$ As condições de satisfação são aquilo que tem de ser dado no mundo para que uma crença seja verdadeira ou um desejo seja realizado.
} 
racterizar a dificuldade para a explicação dos fenômenos mentais da seguinte maneira: se o caráter subjetivo dos estados conscientes é inacessível a descrições objetivas (ou seja, se a descrição de fatos objetivos - tais como processos cerebrais - é incapaz de expressar o caráter subjetivo) e se a forma aspectual dos estados intencionais não pode ser completamente caracterizada por predicados objetivos (inclusive neurofisiológicos) então não parece ser possível traçar uma conexão inteligivel entre os processos cerebrais (objetivos) e os fenômenos mentais - tanto sensações, dotadas de qualia, quanto estados intencionais - (subjetivos). Em outras palavras, parece não ser possível entender esses fenômenos subjetivos como uma consequência de determinados processos cerebrais, já que a descrição de tais processos parece se referir a algo completamente diferente daquilo a que se refere a descrição de fenômenos subjetivos.

Mas, se é assim, o que é então que Searle tem em mente quando afirma que os fenômenos mentais são causalmente explicáveis por processos cerebrais? Em The Rediscovery of the Mind Searle se confronta com uma conhecida concepção dentro da filosofia da mente, segundo a qual a subjetividade dos fenômenos mentais representa um obstáculo decisivo para a explicação desses fenômenos por teorias sobre fenômenos objetivos (como, p. ex., processos cerebrais). Referindo-se ao famoso texto de Thomas Nagel, What it is like to be a bat? (1974), Searle reconstrói o problema da seguinte maneira: no atual estado de nossos conhecimentos não dispomos dos meios conceituais de resolver o problema mentecorpo, pois não temos como explicar o surgimento dos fenômenos mentais a partir da atividade do cérebro. Explicações propriamente ditas, tais como as disponíveis nas 
ciências da natureza, possuem um tipo de necessidade ${ }^{15}$. Entendemos como o comportamento de moléculas de $\mathrm{H}_{2} \mathrm{O}$ corresponde ao estado líquido porque percebemos esse estado enquanto uma consequência necessária daquele comportamento. Se nós entendemos a teoria física pertinente, então é inconcebível para nós que as moléculas tivessem esse comportamento e a água não estivesse no estado líquido. Porém, no caso da consciência e da atividade cerebral, não temos como chegar a esse tipo de necessidade, pois nenhuma descrição de um tipo específico de comportamento neuronal mostraria que um determinado estado de consciência é consequência necessária de tal comportamento (cf. SEARLE, 1992, p. 100-101).

Searle (SEARLE, 1992, p. 100-103; 2004, p. 145-147) apresenta diversos argumentos contra essa concepção ${ }^{16}$, mas no presente contexto é importante examinar apenas um deles, que repousa sobre uma determinada concepção de explanação. O autor (2002b, p. 57-58) coloca, em diversos escritos, que o problema mente-corpo envolve dois tipos de dificuldades: dificuldades empíricas e conceituais. Ele deixa explícito que, quando afirma haver uma solução "simples" para o problema mente-corpo, ele tem em vista as dificuldades conceituais, ou seja, a parte filosófica do problema, sendo que a parte neurobiológica (com suas dificuldades empiricas) estaria de fora dessa solução "simples" 17 . Porém, se-

\footnotetext{
${ }^{15} \mathrm{Na}$ passagem de The Rediscovery of the Mind onde trata desse argumento, Searle caracteriza a necessidade, nesse caso, como "causal”, o que é, no mínimo, estranho, pois Nagel não caracteriza claramente o tipo de necessidade que ele tem em vista.

${ }^{16}$ Uma discussão mais detalhada da argumentação de Searle contra Nagel se encontra em Prata (2009b, p. 148-170).

17 "Eu não posso superar a nossa ignorância da neurobiologia, mas posso ao menos tentar superar nossa confusão conceitual” (SEARLE, 2002b, p. 58).
} 
gundo ele, na medida em que as dificuldades conceituais estivessem resolvidas, o caminho para a resolução das dificuldades empíricas estaria aberto. Nós somente teríamos de esperar que o trabalho das neurociências coloque à nossa disposição uma teoria de como os fenômenos mentais são causados por processos cerebrais e realizados na estrutura do cérebro. Ao se referir à solução dos problemas conceituais, Searle (1992, p. 100) tem em mente, em primeira linha, a superação do dualismo conceitual $^{18}$ que ele afirma ter conseguido. Ao se referir à solução dos problemas neurobiológicos (que notoriamente ainda está longe de ser alcançada), tem em mente uma teoria que seja capaz de estabelecer correlações causais entre os fenômenos mentais e os processos cerebrais. Searle (1992, p. 103) descreve tal teoria da seguinte maneira:

Além disso, podemos e iremos decompor a grande questão - como o cérebro causa a consciência? - em uma porção de questões menores (por exemplo: como a cocaína produz determinadas experiências características). E as respostas detalhadas que estamos começando a dar (por exemplo: a cocaína obstrui a capacidade de determinados receptores sinápticos de reabsorver a norepinefrina) já levam em consideração as inferências características que acompanham a necessidade causal (por exemplo: se você eleva a dose de cocaína, intensifica o efeito).

O ponto que deve ficar claro é o seguinte: Searle tem em mente que tal teoria seria capaz de nos fornecer uma explicação satisfatória. Mesmo que, após a formulação dessa teoria, continuasse a nos parecer concebível que um determinado caráter subjetivo (p. ex. o modo como é vivenciar a experiência produzida pela cocaína) pudesse ser pro-

\footnotetext{
${ }^{18}$ Sobre o dualismo conceitual, cf. Searle (1992, p. 25-26; 2004, p. 115-118).
} 
duzido por outro processo cerebral que não aquele que, de fato, o produz (ou mesmo que nos pareça concebível que esse caráter subjetivo estivesse ausente), mesmo assim nós estaríamos diante de uma explicação satisfatória, pois, como afirma Searle (1992, p. 103): "o conhecimento das relações causais nomológicas [lawlike] nos fornecerá toda a necessidade causal de que precisamos”. Em um de seus livros mais recentes, Mind: A Brief Introduction, Searle (2004, p. 146) descreve o modo como ele pensa que uma explicação dos fenômenos mentais pelos processos cerebrais teria sido alcançada:

Suponha que realmente encontrássemos os vários correlatos neuronais do campo unificado de consciência. Suponha que pudéssemos então, como um segundo passo, mostrar que esses elementos correlacionados fossem de fato causas. Isto é, suponha que pudéssemos por assim dizer - ativar a consciência ao ativar esses processos neurobiológicos e desativar a consciência ao desativar aqueles processos. Suponha, como um terceiro passo, que desenvolvêssemos então uma teoria de como todo o sistema trabalhava. Isto é, suponha que pudéssemos embutir as asserções de correlações causais em asserções de princípios e leis gerais. Me parece que isso é precisamente a estrutura que temos aceitado em outros setores da ciência. (grifos meus)

A esse respeito, ele afirma claramente que a exigência por necessidade, tal como se encontra no trabalho de Nagel, não é justificada, pois a demanda por necessidade, no sentido explicado acima, seria fruto da analogia que se traça entre microfenômenos (como movimentação molecular) e os objetos que nos cercam no dia a dia. Porém, tal necessidade não seria, de acordo com Searle (2004, p. 146-147), uma característica geral das explicações científicas:

Mas não é uma característica geral das explanações em ciência que elas devam expressar algum senso intuitivo de como as coisas devem necessariamen- 
te ocorrer. Ao contrário, a natureza é radicalmente contingente. Muitos dos mais importantes princípios explanatórios em ciência não são de modo algum intuitivos ou óbvios. (grifo meu)

Nesse ponto, sua concepção já se mostra problemática porque ele recorre ao exemplo de leis e fatos físicos básicos, como a equação de Schrödinger ou a constante de Planck, que são algo bastante diverso de propriedades sistêmicas como, de acordo com o naturalismo biológico, os estados de consciência ${ }^{19}$. Porém, o grande problema é que tal concepção do que seria ter explicado os fenômenos mentais pelos processos cerebrais não parece de modo algum satisfatória. A constatação de leis causais regendo a correlação entre processos cerebrais e fenômenos mentais não parece capaz de explicar porque um determinado processo cerebral produz um determinado fenômeno mental, e esse sentido de "explicar", ao contrário do que afirma Searle, não pode ser deixado de lado. Prova disso, no meu entender, é o fato de que se a conexão entre processos cerebrais e fenômenos mentais permanece assim arbitrária, então o sentido de explicação visado por Searle (a constatação de leis causais conectando os dois tipos de fenômenos) parece claramente incapaz de assegurar o caráter biológico do mental (que é exatamente o que Searle pretende), pois se nós temos apenas essas correlações regidas por leis causais, enquanto os dois tipos de fenômenos permanecem, em certo sentido, independentes ${ }^{20}$, então tal teoria (como a que Searle (2004, p.

\footnotetext{
${ }^{19}$ Joseph Levine, que inaugurou o debate sobre a "lacuna explanatória", aceita que fatos naturais básicos, como o valor da constante de gravitação, não possam ser explicados em termos de fenômenos mais fundamentais, mas rejeita que o mesmo se aplique a fenômenos sistêmicos complexos como, também na opinião dele, são os fenômenos mentais (cf. LEVINE, 1983, p. 358).

${ }^{20}$ Permanece sempre concebível que um determinado fenômeno mental fosse produzido por outro processo cerebral, ou que um determinado processo cerebral ocorresse sem que nenhum fenômeno mental fosse
} 
146) pensa ser satisfatória) poderia muito bem ser aceita por um dualista, que afirma haver uma interação causal entre dois âmbitos ontológicos distintos.

\section{O PROBLEMA DAS CAPACIDADES CAUSAIS}

O problema relativo às capacidades causais da consciência se torna claro a partir da consideração das teses, defendidas por Searle, de que as capacidades causais da consciência são idênticas às dos processos cerebrais - tese (1") - e que a consciência é ontologicamente irredutivel a fenômenos objetivos - tese (4b). Se as capacidades são idênticas isso significa que a consciência causa exatamente o que os processos cerebrais causam. Por exemplo, se o meu movimento de ir à geladeira e beber um copo de água é causado pelo meu estado consciente de sede, tal movimento é causado justamente pelo processo cerebral subjacente a este estado (processo que, além do movimento de ir à geladeira, também causa, de acordo com uma concepção muito peculiar defendida por Searle, o próprio estado de sede, sem lacuna temporal). Tal situação pode ser representada pela seguinte figura, derivada das figuras apresentadas por Searle (1983, p. 270) no capítulo final de Intentionality:

produzido, ou ainda é concebível que um fenômeno mental ocorresse sem ser produzido por nenhum processo cerebral. 
Figura 1:

$t_{1}$

$t_{2}$

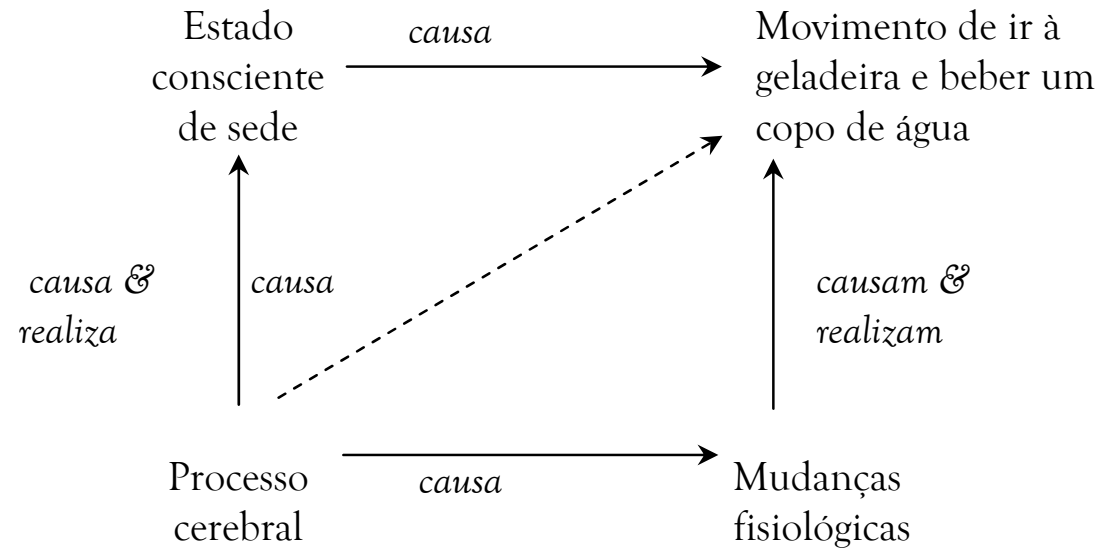

Essa situação parece ser um indício de que o estado de consciência e o processo cerebral subjacente são a mesma entidade, já que eles existem exatamente no mesmo instante de tempo e já que seria estranho que duas entidades diferentes fossem a causa do mesmo efeito. Se eles forem idênticos, então não existem grandes problemas a respeito das capacidades causais da consciência. E, aliás, Searle (2004, p. 127-128) se exprime de modo que indica claramente que ele concebe a identidade das capacidades causais como decorrência da identidade dos fenômenos em questão:

as capacidades causais da consciência são exatamente as mesmas que as do substrato neuronal. Essa situação é exatamente como a das capacidades causais dos objetos sólidos e as capacidades causais de seus constituintes moleculares. Nós não estamos falando sobre duas entidades diferentes, mas sim sobre o mesmo sistema em diferentes níveis. (grifo meu)

Entretanto, a irredutibilidade ontológica da consciência a quaisquer fenômenos objetivos (tais como os processos cerebrais) parece absolutamente incompatível com asserções de identidade entre a consciência e a atividade do cérebro (tal como a asserção que se encontra na passagem citada a- 
cima). Searle (1992, p. 112-113) considera a redutibilidade como uma forma peculiar de relação de identidade que, porém, não subsistiria no caso da consciência e dos processos cerebrais (ibid., p. 117) ${ }^{21}$. Sendo assim, a irredutibilidade ontológica parece estar em contradição com a identidade que, na concepção do autor, decorre da identidade de capacidades causais (a questão da identidade será discutida de modo mais detalhado na seção "O problema da identidade", apresentada a seguir).

No entanto, além de ser incompatível com a identidade entre a consciência e os processos cerebrais, a irredutibilidade ontológica gera difíceis problemas a respeito das capacidades causais da consciência: se a consciência e a atividade cerebral não são idênticas, então como compreender a identidade das capacidades causais? À primeira vista, duas opções se delineiam, mas nenhuma delas está disponível para o naturalismo biológico. Uma possibilidade seria aceitar que os efeitos da consciência e da atividade cerebral possuem, simultaneamente, duas causas, a chamada sobredeterminação causal, que Searle (2002b, p. 62) rejeita explicitamente e que, de fato, não me parece ser uma opção viável $^{22}$. Outra possibilidade seria negar a eficácia causal da consciência (já que negar a eficácia causal da atividade cerebral seria descabido), ou seja, abraçar o assim chamado epifenomenalismo, mas uma solução desse tipo é incompatível com o naturalismo biológico, já que Searle (2004, p. 114)

\footnotetext{
${ }^{21}$ Searle (1992, p. 113) afirma que essa irredutibilidade ontológica coexiste com a redutibilidade causal explicada anteriormente (cf. "Reconstruindo a teoria de Searle"). Na concepção do autor, a consciência seria ontologicamente reduzida a processos cerebrais se ela fosse "nada além" (nothing but) de processos cerebrais. ${ }^{22}$ Cf. p. ex. Kim (1995, p. 193).
} 
defende veementemente a eficácia causal dos fenômenos mentais.

Essa problemática se mostra ainda mais difícil quando se observa que (apesar das recusas mencionadas no parágrafo anterior) é possível encontrar base textual para a interpretação de que Searle se compromete tanto com o epifenomenalismo quanto com a sobredeterminação. Por um lado, a concepção da consciência como causalmente redutível à atividade cerebral pode perfeitamente ser interpretada como uma adesão ao epifenomenalismo, o que é reforçado por sua defesa da irredutibilidade ontológica ${ }^{23}$. Ao formular a redutibilidade causal da consciência, ele (2002b, p. 60) escreve de modo bastante sugestivo: "Consciência é causalmente redutível a processos cerebrais, porque [...] a consciência não tem capacidades causais por si mesma em adição às capacidades causais da neurobiologia subjacente" (grifo meu). Por outro lado, ao defender a eficácia causal da consciência e a irredutibilidade ontológica, Searle parece irremediavelmente comprometido com a sobredeterminação, especialmente considerando-se o fato de que não teria como, em sã consciência, negar a eficácia causal dos processos cerebrais ${ }^{24}$. Para perceber como sua teoria

\footnotetext{
${ }^{23}$ A aparente negação da eficácia causal da consciência e sua conexão com a irredutibilidade ontológica (negação da identidade), são expostas, de modo bastante claro, por Tim Crane (1993, p. 319-320): "Searle nega que as características superficiais (incluindo propriedades mentais) são 'emergentes' no sentido de que elas tenham capacidades causais independentemente das capacidades causais de suas partes físicas (p. 112). Em lugar disso, ele acha que essas propriedades podem ser 'causalmente reduzidas' às suas propriedades físicas subjacentes (pp. 114-15). Mas onde isso deixa as capacidades causais do mental? Suponhamos que minha dor neste momento me faça (causes me) gritar. Se, como Searle afirma, as capacidades causais da dor são 'inteiramente explicáveis' (p. 114) em termos das capacidades causais do meu estado neuronal neste momento, então (dada a negação da teoria da identidade por Searle) existe claramente um sentido no qual minha dor não é a causa do meu grito" (grifo meu). As páginas indicadas por Crane são de Searle (1992).

${ }^{24} \mathrm{Na}$ verdade, como seria de se esperar de um filósofo tão afeito ao estudo das neurociências, Searle (1983, p. 269-270) reconhece sem problemas que os processos cerebrais são causalmente eficazes sobre nossas ações: "Embora nós saibamos pouco sobre como a ação intencional se origina no cérebro, nós sabemos que mecanismos neurais estimulam movimentos musculares".
} 
está envolvida com a tese da sobredeterminação basta observar a figura 1 . Se o processo cerebral que causa e realiza um estado consciente de sede não é idêntico a tal estado (ao qual Searle atribui eficácia causal) e se tanto o processo cerebral quanto o estado consciente são causas do movimento à geladeira, então esse movimento é sobredeterminado, o que é representado na figura pelas duas setas (representativas da causação) convergindo para o mesmo efeito.

Se tudo se articula nesses termos, então a teoria de Searle acerca da relação entre mente e corpo parece ser incoerente, aparência que se torna ainda mais flagrante se considerarmos que, a partir de algumas das teses básicas enunciadas anteriormente, em conjunto com algumas das teses discutidas na presente seção, parece ser possível deduzir asserções que contradizem algumas dessas teses. Voltemos nossa atenção para as seguintes asserções:

(4b) A consciência é ontologicamente irredutivel (não é idêntica) a fenômenos objetivos

(5) A consciência é causalmente eficaz

(6) Processos cerebrais causam nossas ações

(7) Nossas ações não são sobredeterminadas

De (4b), (5) e (6) segue-se:

(C1) Nossas ações são sobredeterminadas

De (4b), (6) e (7) segue-se:

(C2) A consciência é causalmente ineficaz ${ }^{25}$

\footnotetext{
${ }^{25}$ A tese de que é possível deduzir essas duas conclusões contraditórias com as premissas de Searle é discutida de modo mais detalhado em Prata (2008b, p. 19-28).
} 
Considerando a plausibilidade das teses (5), (6) e (7) para as quais se encontram muitos defensores no debate acerca do problema mente-corpo - me parece que a resolução dessa inconsistência exige uma consideração mais atenta da tese (4b) de que a consciência e a atividade cerebral não são idênticas. Penso que a reflexão acerca da noção de identidade seria um passo muito importante para a resolução desse problema acerca das capacidades causais.

\section{O PROBLEMA DA IDENTIDADE}

Conforme discutido na seção anterior, Searle parece, em diversas passagens, defender a tese da identidade entre a consciência e os processos cerebrais, em especial quando ele defende a identidade das capacidades causais de ambos. Nesse sentido, pode-se afirmar que uma identificação entre a consciência e a atividade cerebral decorre da primeira tese do naturalismo biológico discutida acima, a da causação da consciência pelos processos do cérebro, que, de acordo com o autor, implica a redutibilidade causal e, por sua vez, a identidade das capacidades causais.

(1) A consciência é causada por processos cerebrais

(1") As capacidades causais da consciência são idênticas às dos processos cerebrais

Para entender como a identidade das capacidades causais parece implicar a identidade entre os fenômenos em questão, é importante refletir acerca de algumas afirmações de Searle a respeito das capacidades causais da consciência. 
Em Intrinsic Intentionality ele (1980b, p. 455) recusa o epifenomenalismo (isto é, a ineficácia causal) dos fenômenos mentais nos seguintes termos:

Estados mentais não são mais epifenomênicos do que a elasticidade e a resistência a perfurações de um pneu de carro cheio são, e as interações podem ser descritas tanto no nivel superior quanto no nivel inferior, exatamente como no caso análogo do pneu. (grifo meu)

Em primeiro lugar, a comparação dos fenômenos mentais com propriedades físicas tais como elasticidade e resistência, que podem ser identificadas, enquanto tipos, com determinados tipos de comportamento molecular, pode dar a entender que Searle tem em vista uma identificação de tipos entre a consciência e o comportamento neuronal, o que corresponderia ao reducionismo clássico em filosofia da mente (p. ex. em Place, Smart e Feigl). Em segundo lugar, a afirmação de que as interações causais podem ser descritas tanto no micro quanto no macronível também sugere que Searle pretende efetuar alguma forma de identificação. Para elucidar esse segundo ponto, é interessante observar sua concepção a respeito desses níveis de descrição (micro e macro).

No último capítulo do livro Intentionality, ele procura elucidar a eficácia causal dos fenômenos mentais a partir do modelo de fenômenos extremamente comuns na natureza, e, para isso, recorre a um diagrama para representar as relações causais em diferentes níveis de descrição. Se uma intenção em ação em um determinado tempo $t_{1}$ causa um movimento corporal no tempo $t_{2}$, deve-se aceitar, em virtude das teses (1) e (2) do naturalismo biológico, que esses fenômenos são causados e realizados por fenômenos no micronível nesses respectivos tempos: 
Figura 2:

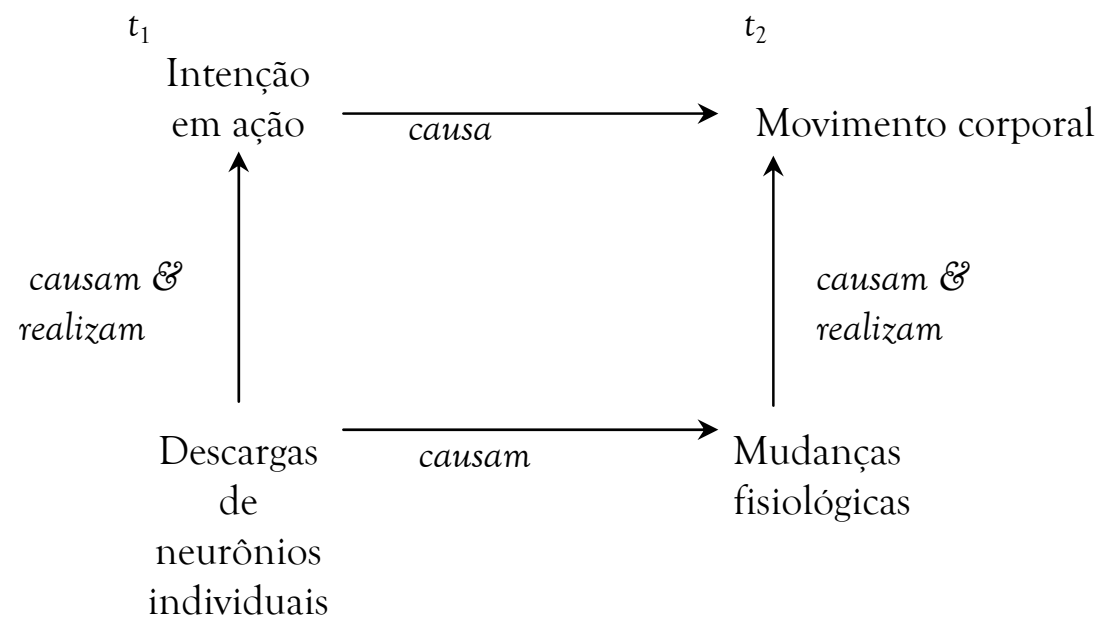

A respeito dos fenômenos que ocorrem nos dois níveis de descrição, afirma: "os fenômenos em $t_{1}$ e $t_{2}$ respectivamente são os mesmos fenômenos descritos em diferentes níveis de descrição" (SEARLE, 1983, p. 269, grifo meu). Ou seja, a intenção em ação é exatamente o conjunto das descargas neuronais descritas em nível macro, assim como o movimento corporal é exatamente o conjunto de mudanças fisiológicas descrito no nível superior. Outro forte indício de que Searle defende alguma variante da tese da identidade entre a consciência e a atividade do cérebro é a sua afirmação de que as relações causais também podem ser consideradas como ocorrendo entre os níveis, seja do macro para o micro, seja do micro para o macro. Nesse sentido, seria possível, de acordo com ele (idem, p. 270), traçar linhas diagonais no diagrama acima, as quais "mostrariam que a intenção em ação causa mudanças neurofisiológicas e que as descargas neuronais causam movimentos corporais": 
Figura 3:

$t_{1}$

$t_{2}$

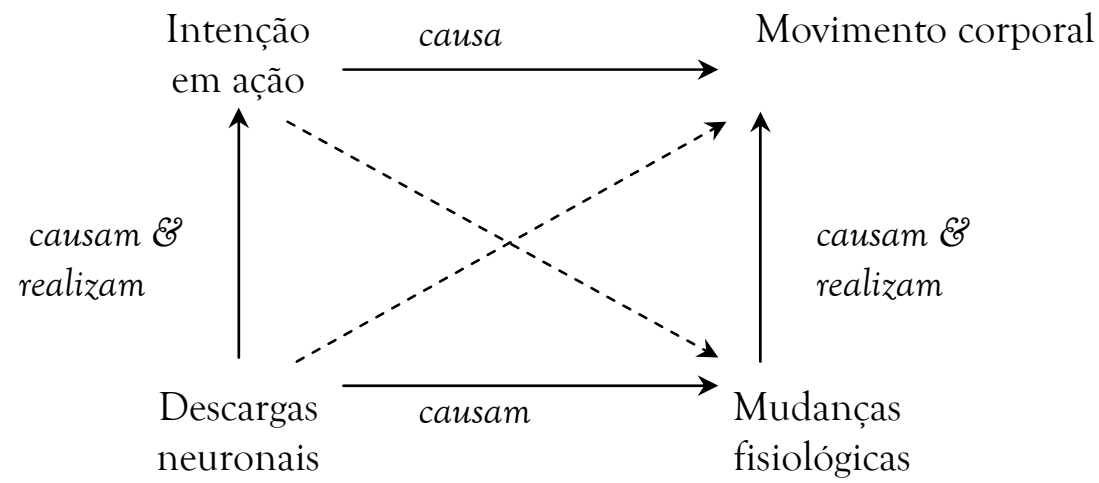

A existência simultânea dos fenômenos que ocorrem, respectivamente, em $t_{1}$ e $t_{2}$, bem como a relação causal descrita de diferentes perspectivas (nos níveis macro e micro, e também de um para o outro), parecem ter como resultado que se trata de uma identidade entre as descargas neuronais e a intenção (assim como entre as mudanças fisiológicas e o movimento). Em um texto posterior, Searle novamente caracteriza a suposta identidade das capacidades causais da consciência e da atividade cerebral de um modo que parece considerá-la decorrente da identidade dos próprios fenômenos em questão. Tomando como exemplo uma situação em que um fenômeno mental causa outro fenômeno mental, ele (1995, p. 219) escreve:

Eu agora, deixe-nos supor, tenho uma sensação consciente de dor. Esta é causada por padrões de descargas neuronais e é realizada no sistema de neurônios. Suponha que a dor cause um desejo de tomar aspirina. $O$ desejo também é causado por padrões de descargas neuronais e é realizado no sistema de neurônios. [...] Eu posso com razão dizer tanto que minha dor causou meu desejo quanto que seqüências de descargas neuronais causaram outras seqüências. Esses são duas descrições diferentes, embora consistentes, do mesmo sistema, dadas em níveis diferentes. 
Mais uma vez temos duas descrições que, de acordo com o autor, se referem ao mesmo sistema e a determinados processos que nele ocorrem. Mais exatamente, temos uma relação causal descrita em dois níveis, o que parece comprometer Searle com a identidade dos fenômenos descritos nesses diferentes níveis. $\mathrm{O}$ modo como ele se expressa na passagem citada não deixa grande margem para dúvidas: as relações causais representadas nas linhas horizontais do diagrama abaixo são, na realidade, uma só:

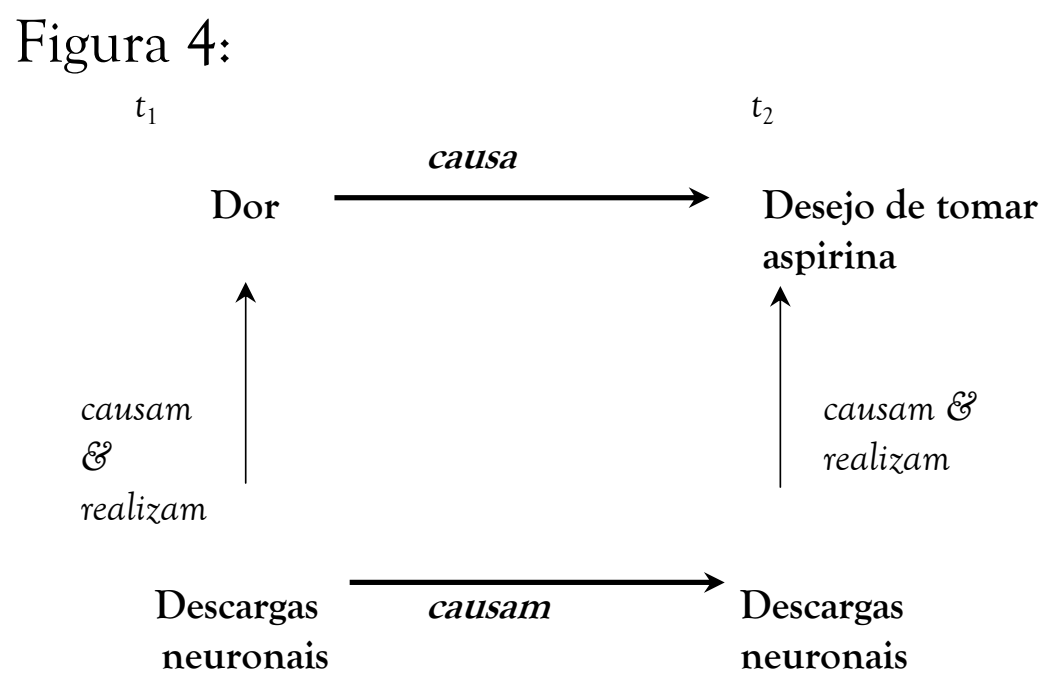

Até este ponto, foi examinado, em linhas gerais ${ }^{26}$, o modo como a tese da identidade das capacidades causais da consciência e da atividade cerebral parece implicar a identidade de ambas. Mas essa identidade também está envolvida com a tese (2) discutida na seção "Reconstituindo a teoria de Searle”. Ao defender que a consciência é realizada no sis-

\footnotetext{
${ }^{26} \mathrm{Um}$ dos aspectos que poderia ter sido mais aprofundado é o seguinte: apesar de afirmar que a consciência é causada por processos cerebrais, Searle não pretende se comprometer, em virtude dessa causação, com a diferença entre a causa e o efeito. A causação, nos casos em que está acompanhada da realização, ocorre entre diferentes níveis do mesmo sistema: "Processos cerebrais causam a consciência, mas a consciência que eles causam não é uma substância ou entidade extra. Ela é apenas uma característica de nível superior do sistema inteiro" (SEARLE, 2002a, p. 9, grifo meu; cf. SEARLE, 1983, p. 266).
} 
tema cerebral, Searle (1992, p. 111) a concebe como uma propriedade sistêmica, isto é, uma propriedade que só pode ser atribuída a um sistema dotado da devida complexidade, e a concepção da consciência enquanto propriedade sistêmica parece levar ao resultado de que a consciência (macro) e os processos cerebrais (micro) são o mesmo fenômeno descrito em diferentes níveis. Ao explicar sua concepção de realização usando o caso das propriedades de liquidez da água, ele (1983, p. 266) escreve:

a liquidez de uma porção de água não é algum suco extra secretado pelas moléculas de $\mathrm{H}_{2} \mathrm{O}$. Quando descrevemos o material como líquido estamos apenas descrevendo aquelas mesmas moléculas em um nível de descrição superior ao nível das moléculas individuais. (grifo meu)

A partir dessa discussão, podemos enunciar as teses (relevantes no presente contexto) que integram a teoria de Searle:

(2) A consciência é realizada no sistema cerebral

(2b) A consciência é uma propriedade sistêmica do cérebro

(2') A consciência e os processos cerebrais são o mesmo fenômeno descrito em diferentes níveis

A tese (2') é uma asserção de identidade entre a consciência e os processos que ocorrem no cérebro, o que, por um lado, resolveria o problema das capacidades causais (o epifenomenalismo e a sobredeterminação, nesse caso, não se colocariam), mas, por outro lado, estaria em contradição com a tese da irredutibilidade ontológica da consciência. Por motivos de espaço, não é possível discutir detalhada- 
mente aqui a tese da irredutibilidade ontológica da consciência e suas implicações ${ }^{27}$. Mas, para perceber o problema que ela acarreta, basta comparar as passagens citadas acima, onde o autor parece defender a tese da identidade, com a seguinte afirmação a respeito da redução da consciência: "Consciência é, de modo completo, causalmente explicável pelo comportamento neuronal mas não é, em virtude disso, mostrada como sendo nada além de comportamento neuronal" (SEARLE, 2004, p. 119, grifo meu). Aqui, Searle nega a identidade entre consciência e processos cerebrais, o que vai de encontro a todas as considerações já expostas na presente seção. Entretanto, a solução para essa (pelo menos aparente) contradição talvez possa ser encontrada através da reflexão acerca do sentido de identidade de que se trata aqui.

Em um de seus mais recentes trabalhos, Searle (2004, p. 110) desdenha do valor da noção de identidade para a solução do problema mente-corpo, afirmando que, no caso dos eventos mentais, não é tão simples encontrar critérios para realizar uma identificação - diferente do caso de objetos e compostos. No caso dos eventos, estamos lidando com entidades que possuem múltiplas características, cuja descrição depende de nossos interesses em cada caso. Nas palavras do autor (idem, p. 124-125, grifos meus): "Pareceme que nós podemos tratar um e o mesmo evento como tendo ambas, características neurobiológicas e características fenomenológicas. Um e o mesmo evento é uma seqüência de descargas neuronais e é também doloroso". A concepção acerca dos eventos mentais exposta nessa passagem aproxima estreitamente o naturalismo biológico da teoria da iden-

\footnotetext{
${ }^{27}$ A esse respeito, cf. Searle (1992, p. 116-124; 2004, p. 118-123).
} 
tidade de ocorrências (token identity), segundo a qual os eventos são entendidos enquanto concretos particulares que, por sua vez, possuem diversas propriedades e pertencem a diversos tipos (cf. KIM, 1996, p. 58). O ponto central dessa concepção é que toda ocorrência particular de um tipo de fenômeno mental (p. ex. a dor) também cai sob um tipo de evento físico (p. ex. um processo cerebral). Nas palavras de Jaegwon Kim (1996, p. 59): "todo evento que cai sob um tipo de evento mental também cai sob um tipo de evento físico (ou todo evento que tem uma propriedade mental também tem alguma propriedade física".

$\mathrm{Na}$ passagem onde ele discute a noção de identidade, Searle faz referência a esse mesmo texto de Kim, recorrendo a um exemplo deste último para ilustrar a identidade de ocorrências. A questão é que, ao fazer isso, ele (2004, p. 125) aceita a tese da identidade de ocorrências para o caso da consciência e da atividade cerebral:

O caso é um pouco como o exemplo de Jaegwon Kim para identidade de ocorrências. Toda ocorrência de objeto colorido é idêntica a uma ocorrência de objeto dotado de forma. Não há dúvida de que isso é verdadeiro, mas isso não mostra que ser colorido e ter uma forma são a mesma coisa. Do mesmo modo, podemos ter uma noção de processo neurobiológico grande o suficiente de modo que toda ocorrência de processo de dor é uma ocorrência de processo neurobiológico no cérebro, mas disso não se segue que a sensação dolorosa de primeira pessoa é a mesma coisa que o processo neurobiológico de terceira pessoa. (grifos meus)

Em virtude dessa simultânea identidade (de ocorrências) e diferença (de tipos), Searle recomenda o abandono da noção de identidade na discussão sobre o problema mentecorpo. Em que medida essa é uma recomendação sensata é uma questão que não poderá ser abordada neste lugar. Mas 
o ponto relevante para nossa discussão é que essa aceitação da identidade de ocorrências poderia resolver a aparente contradição entre as passagens discutidas acima: ao afirmar e negar, em diferentes passagens de sua obra, a identidade entre a consciência e a atividade cerebral Searle teria em vista aspectos diferentes da identidade.

Lembrando os diagramas apresentados, deve-se notar que a afirmação de Searle é que os fenômenos que ocorrem nos tempos $t_{1}$ e $t_{2}$ são os mesmos fenômenos, e essa referência a tempos determinados poderia ser interpretada como mais um indício de que se tratam, na concepção do autor, de concretos particulares, os quais, apesar de numericamente idênticos, poderiam ter propriedades subjetivas e objetivas (mutuamente irredutíveis). Porém, uma evidência ainda mais forte para essa interpretação (de Searle como defensor da identidade de ocorrências) se encontra, no meu entender, em uma das primeiras formulações da irredutibilidade ontológica na obra de Searle. Em uma passagem de The Rediscovery of the Mind ele (1992, p. 117) escreve:

Suponha que tentássemos dizer que a dor é na verdade "nada exceto” os padrões de descargas de neurônios. Bem, se tentássemos tal redução ontológica, as características essenciais da dor seriam deixadas de lado. Nenhuma descrição dos fatos de terceira pessoa, objetivos, fisiológicos, expressaria o caráter subjetivo, de primeira pessoa, da dor, simplesmente porque as características de primeira pessoa são diferentes das características de terceira pessoa. (grifos meus).

Aqui, a irredutibilidade ontológica é apresentada como algo relativo às características (features) da consciência e dos processos cerebrais, o que seria, em princípio, perfeitamente compatível com uma identidade de ocorrências entre eventos mentais e físicos. Em outras palavras, a aparente contra- 
dição entre a identidade da consciência com processos cerebrais e a irredutibilidade ontológica pode, talvez, ser apenas aparente.

\section{CONSIDERAÇÕES FINAIS}

O presente trabalho pôs em destaque as grandes questões suscitadas pela reflexão sobre o naturalismo biológico de Searle, questões de cujo exame depende o julgamento sobre a viabilidade ou não dessa teoria. A discussão detalhada dos problemas levantados nas três seções anteriores exigiria um espaço que extrapola os limites do presente texto. Sendo assim, tratarei aqui de alguns aspectos gerais desses problemas, cuja discussão iniciei em outros trabalhos (cf. PRATA, 2008a, 2008b, 2009a, 2009b) e pretendo aprofundar em futuros artigos. Um primeiro aspecto a ser ressaltado é que os três problemas aqui discutidos podem ser concebidos como a incompatibilidade entre teses que são defendidas por Searle e, provavelmente, a solução exigirá que algumas delas sejam abandonadas. Consideremos as seguintes asserções:

a) Explanabilidade:

(1') As características da consciência são causalmente explicáveis através dos processos cerebrais

(4b') As características da consciência não podem ser expressas em termos objetivos

b) Capacidades causais:

(1") As capacidades causais da consciência são idênticas às dos processos cerebrais 
(4b) A consciência é ontologicamente irredutivel (não é idêntica) a fenômenos objetivos

c) Identidade:

(2') A consciência e os processos cerebrais são o mesmo fenômeno descrito em diferentes níveis

(4b) A consciência é ontologicamente irredutivel (não é idêntica) a fenômenos objetivos

Um ponto que chama a atenção é que a tese (4b) - e uma de suas consequências, (4b') - está envolvida no surgimento de todos esses problemas, ao passo que os outros membros de cada par - (1'), (1”) e (2') - são bastante diferentes entre si. Isso mostra, no meu entender, que a tese da irredutibilidade ontológica perpassa os principais problemas da teoria em questão, tornando a reflexão sobre a irredutibilidade imprescindível para a resolução desses problemas.

Sobre o problema da explanabilidade, devo enfatizar que não é meu propósito defender a tese da lacuna explanatória (sustentada por autores como Joseph Levine e David Chalmers) contra Searle. Na seção "O problema da explanabilidade" eu pretendia apenas mostrar que a concepção de explanação do autor (no que ela se baseia em meras correlações causais) está abaixo do nível atual desse debate ${ }^{28}$. Sobre

\footnotetext{
28 “Como tem sido claramente salientado por Levine, Chalmers e outros, o ponto não é que nós não poderíamos ter conhecimento de leis naturais que conectem estados cerebrais em termos de sua microsestrutura com instanciações de propriedades c. [...] É claro que podemos saber da conexão nomológica entre estados cerebrais e a experiência da alegria e ainda assim não ter nenhum entendimento de como é o caso que um cérebro com uma certa microestrutura (a) leva ao surgimento de um sujeito de experiência e (b) causa a ocorrência do tipo qualitativo específico em questão" (NIDA-RÜMELIN, 2002, p. 216). De acordo com a autora, "c-properties" são propriedades essencialmente ligadas à experiência consciente.
} 
os dois últimos problemas, penso que uma reflexão mais cuidadosa sobre a noção de identidade (que levasse em conta, por exemplo, a distinção entre identidade de ocorrências e identidade de tipos) poderia eliminar a aparente incoerência do naturalismo biológico a respeito da identidade da consciência com processos cerebrais e seria, também, importante para a resolução do problema das capacidades causais. Entretanto, não estou certo se a identidade de ocorrências em conjunto com a diferença (irredutibilidade) de tipos é suficiente para resolver completamente esse problema, pois, embora a identidade de ocorrências afaste o problema da sobredeterminação, receio que a irredutibilidade das propriedades mentais ainda deixe o naturalismo biológico de Searle nas garras do epifenomenalismo.

Abstract: The paper aims at giving a general exposition of John Searle's solution of the mind-body problem - biological naturalism - and examines its fundamental theses, and some of its consequences. The exam of such theses - which delineates the characteristics of Searle's theory - shows that the theory has three main difficulties, since it holds some assertions which at first sight seem to be incompatible.

Keywords: mind-body problem, Searle, reduction, mental causation.

\section{REFERÊNCIAS}

CORCORAN, K. The Trouble with Searle's Biological Naturalism. Erkenntnis, v. 55, n. 3, p. 307-324, 2001.

CHURCHLAND, P. Betty Crocker's Theory [Review on The Rediscovery of The Mind]. London Review of Books, v. XVI, n. 9, p. 13-14, 12 May 1994. 
CRANE, T. Review on The Rediscovery of The Mind. International Journal of Philosophical Studies, v. 1, n. 2, September 1993.

KIM, J. Mental Causation in Searle's 'Biological Naturalism'. Philosophy and phenomenological Research, v. 55, n. 1, p. 189-194, march 1995.

. Philosophy of Mind. Oxford, Boulder: Westview Press, 1996.

LEVINE, J. Materialism and Qualia: The Explanatory Gap. Pacific Philosophical Quarterly, n. 64, p. 354-361, 1983.

NIDA-RÜMELIN, M. Causal Reduction, Ontological Reduction and First-Person Ontology. Notes on Searle's Views about Consciousness. In: GREWENDORF, G.; MEGGLE, G. (Org.) Speech Acts, Mind and Social Reality: Discussions with John R. Searle. Dordrecht, Boston, London: Kluwer Academic Publishers. 2002. p. 205-221.

PRATA, T. A. There can be causal without ontological reducibility of consciousness? Troubles with Searle's account of reduction. In: Reduction and Elimination in Philosophy and the Sciences: Papers of the 31st International Wittgenstein Symposium. Kirchberg am Wechsel (Áustria): Austrian Ludwig Wittgenstein Society, 2008a. p. 55-57.

- Dificuldades da concepção de John Searle sobre a redução da consciência: o problema das capacidades causais. Princípios, v. 15, n. 24, p. 5-29, 2008b. 
- Irredutibilidade ontológica versus identidade:

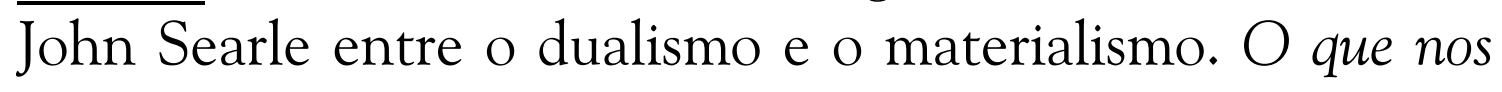
faz Pensar, n. 25, p. 107-124, 2009a.

. Pode-se explicar a consciência através de processos cerebrais? A argumentação de John Searle contra a concepção de Thomas Nagel. Kalagatos - Revista de Filosofia, v. 6, n. 11, p. 137-172, inverno de 2009b.

SEARLE, J. R. Minds, Brains and Programs. Behavioural and Brain Sciences 3, p. 417-424, 1980a.

- Intrinsic Intentionality. Behavioral and Brain Sciences 3, p. 450-456, 1980 b.

. Intentionality: an Essay in the Philosophy of Mind. Cambridge: Cambridge University Press, 1983.

. Minds, Brains, and Science. Cambridge Mass.,: Harvard University Press, 1984.

. The Rediscovery of the Mind. Cambridge Mass., London: MIT Press, 1992.

. Searle, John. In: GUTTENPLAN, S. (Ed.). A Companion to the Philosophy of Mind. Oxford/Cambridge MA: Basil Blackwell, 1994.

. Consciousness, the Brain and the Connection Principle: a Reply. Philosophy and Phenomenological Research, v. LV, n. 1, p. 217-232, March 1995.

- Consciousness and Language. Cambridge (UK): Cambridge University Press, 2002a. 
. Why I Am Not a Property Dualist. Journal of Consciousness Studies, v. 9, n. 12, p. 57-64, 2002 b.

. Mind: a Brief Introduction. Oxford: Oxford University Press, 2004.

THOMPSON, D. Intentionality and causality in John Searle. Canadian Journal of Philosophy 16, p. 83-97, 1986. 